\title{
E1 color y su significado en los documentos cartográficos del Cuerpo de Ingenieros Militares del siglo XVIII
}

\author{
María Giménez Prades, Margarita San Andrés Moya, José Manuel de la Roja de la Roja
}

Resumen: Los Documentos Cartográficos del Cuerpo de Ingenieros Militares del s. XVIII y las fuentes documentales asociadas a su ejecución tienen un gran interés histórico, artístico y cultural. En este artículo se analizan las fuentes relacionadas con las técnicas, los materiales y sus formas de aplicación. Se describen los pigmentos y colorantes recogidos en los distintos tratados relacionados con este arte, especialmente los referidos a la técnica del lavado, en los que, además, se hace referencia a los códigos de color según el elemento representado, el orden o secuencia de trabajo y las mezclas de colores. Puesto que se trata de documentos que en aquella época tuvieron una función eminentemente práctica, en su ejecución se seguían unas pautas determinadas, que permitían normalizar su lectura e interpretación. Desde la perspectiva de la Conservación-Restauración, la documentación estudiada aporta una información significativa relacionada con los materiales sobre los que se intervienen, la detección de procesos de degradación y la autentificación de documentos.

Palabras clave: pigmentos, colorantes, color, técnica del lavado, cartografía, Cuerpo de Ingenieros Militares

Abstract: The cartographic documents realized for the $18^{\text {th }}$ century Military Engineers Corps and the documentary sources related to its accomplishment are of historical, artistic and cultural interest. In this paper sources related to techniques, materials and its application are analyzed. Pigments and colorants named in this literature are described, specially recounted to the wash method. In these documentary sources are also described the code of colour applied depending on the represented element, the order or sequence of work and the mixture of colours. These cartographic documents had an eminently practical function, so in its accomplishment were following certain guidelines, which were allowing normalize its reading and interpretation. The documents studied contribute a significant information related to a collection which has to be conserved.

Keywords: pigments, dyes, colour, wash method, cartography, Military Engineers Corps

Resumo: Os documentos cartográficos do Corpo de Engenheiros Militares do século XVIII e as fontes documentais associadas à sua execução têm um grande interesse histórico, artístico e cultural. Neste artigo analizam-se as fontes relacionadas com as têcnicas, os materiais e as suas formas de aplicação. Descrevem-se os pigmentos e corantes recolhidos nos diferentes tratados relacionados com esta arte, especialmente os referidos à têcnica do lavado, nas quais se faz referência aos códigos de cor segundo o elemento representado, a ordem ou sequência do trabalho e as misturas de cores. Dado que se trata de documentos em que naquela época tiveram uma função eminentemente práctica, na sua execução seguiam umas pautas determinadas, que permitiam normalizar a sua leitura e interpretação. Desde a perspectiva da Conservação-Restauração, a documentação estudada aporta uma informação significativa relacionada com os materiais sobre os que se intervêem, a detecção de processos de degradação e da autentificação de documentos.

Palavras-chave: pigmentos, corantes, cor, têcnica do lavagem, cartografia, Corpo de Engenheiros Militares.

\section{Introducción}

Durante el s. XVIII se produjo en España un desarrollo socio-cultural que, al igual que en el resto de Europa, permitió establecer las bases de la sociedad moderna. Dentro de este contexto se crea el Cuerpo de Ingenieros Militares, constituido por arquitectos, ingenieros, delineantes y topógrafos. Entre sus funciones estaba el reconocimiento y realización de planos, junto con el seguimiento y ejecución de obras como fortificaciones, almacenes, cuarteles, muelles y otras fábricas Reales. La información relativa a este Cuerpo aportada por Ordenanzas, Reales Decretos, tratados técnicos, 
tratados de dibujo y cuadernos de apuntes, junto con los documentos cartográficos que ejecutaron, constituyen una fuente documental relevante del conocimiento científico y artístico. Estos documentos constituyen un claro ejemplo de los resultados de la unión de la ciencia y el arte. Por una parte, muestran el desarrollo técnico alcanzado en aquella época para realizar los levantamientos topográficos y, por otra, la destreza artística que subyace en la plasmación cartográfica; todo ello perfectamente sistematizado de acuerdo a una serie de directrices previamente establecidas (Giménez 2007).

Los antecedentes de su creación surgen en la guerra de Sucesión (1701 - 1713), conflicto bélico internacional motivado por el nombramiento de Felipe V de Borbón como rey de España en 1700, tras la muerte de Carlos II de Habsburgo ${ }^{1}$. Muy pronto resultó evidente la escasez de ingenieros y la necesidad de dotarles de conocimientos técnicos apropiados. Esta situación fue subsanada por Luis XIV de Francia que en 1704 manda algunos oficiales para la campaña de Portugal. Finalmente, en 1711 Felipe V crea el Cuerpo de Ingenieros Militares y en 1716 inaugura la Real y Militar Academia de Matemáticas de Barcelona que empieza a funcionar en 1720 (Capel et al. 1988).

Como todos los cuerpos militares, el de Ingenieros se regía por unas ordenanzas en las que se establecen sus funciones, los reglamentos de las Academias, su sistema de educación y las asignaturas impartidas (Portugués 1803). Su producción cartográfica fue muy importante y obedecía a unas normas muy precisas relacionadas con los materiales, orden de aplicación y código de colores. Estas normas aparecen recogidas en distintos tipos de fuentes documentales entre las que destacan los textos académicos de carácter artístico. Dentro de éstos se pueden establecer dos categorías: tratados de dibujo y lavado y cuadernos de apuntes. Los tratados versan sobre la plasmación de un elemento constructivo en un soporte de papel; con esta finalidad describen los colores utilizados, su preparación y, además, explican el uso de un código de color para cada uno de los elementos de una fortificación o un plano de población. Los cuadernos de apuntes son textos docentes escritos por los propios ingenieros y aportan una valiosa información sobre el color, las tintas y los materiales a utilizar. En los siguientes apartados se describen estas fuentes y la información que en ellas se recoge.

\section{Fuentes documentales}

Los tratados de dibujo y lavado consultados han sido los siguientes:

L'art de laver, ou nouvelle manière de peindre sur le papier suivant le coloris des desseins qu'on envoye à la Cour, impreso en Lyon en 1687. Se trata del primer manual sobre la acuarela aplicada a los dibujos arquitectónicos. Su autor, H. Gautier de Nismes, fue Ingeniero e Inspector general de Puentes y Carreteras. Describe las características del dibujo sombreado en monocromo, los diferentes soportes, colores, aglutinantes y los procedimientos. Contiene un compendio en el que se relacionan por orden alfabético los colores que deberán ser aplicados a cada parte de la construcción.

L'Art de Dessiner propement les Plans, Profils, Elevations Geometrales et Perspectives soit d'Architecture Militaire et Civile avec tous les secrets les plus rares pour faire les couleurs avec lesquelles les Ingenieurs represent les divers materiaux d'une Place. Libro anónimo impreso en París en 1697 por Ch. Ballard, en el que se explican las reglas del dibujo y el lavado de planos. Incluye un interesante recetario para la preparación de pigmentos y colorantes, colas y aglutinantes; además de consejos para la aplicación de los colores.

Les Règles du Dessein et du Lavis pour les plans des ouvrages et des bâtimens, tant de l'Architecture militaire que civile. La primera edición data de 1722 (Paris). En este caso se ha consultado la edición de 1743, también impresa en Paris. Su autor, M. Buchotte, fue ingeniero real y describe los materiales a utilizar: papel, lápiz, plumas, pigmentos, así como su correcta aplicación. También contiene reglas para el dibujo y el lavado de planos. 
Método Práctico para el Dibujo Lavado, Pintura de Aguada y de Iluminación. Este tratado es posterior a los anteriores, está impreso en Barcelona en 1833 y su autor es conocido como D. J. A. y L. Puede considerarse un tratado teórico del dibujo lavado. Recomienda el uso de determinados colores, su modo de aplicación, cómo preparar aglutinantes y los papeles utilizados para la reproducción de dibujos.

Además de estos textos, se ha consultado la aportación de M. C. Hidalgo, que en 1980 publica el hallazgo de un cuadernillo del s. XIX constituido por tres breves tratados, uno de los cuales se refiere a "Los colores propios para delinear y lavar los planos" (Hidalgo 1980). Se trata de un texto anónimo de tan solo cinco páginas y dividido en tres partes. En la primera se describen los pigmentos utilizados para colorear los planos y su preparación. La segunda parte trata sobre la mezcla de los pigmentos, las características del color resultante, y el uso de los distintos colores en relación a los elementos o áreas representadas en el plano. La tercera y última parte comprende una serie de observaciones y consejos relacionados con la realización práctica de los planos.

En todos estos textos, las reglas y el código del color coinciden, lo que lleva a la conclusión de que existía una normalización, que no aparece en ordenanzas ni reales órdenes, pero sí se menciona en este tipo de fuentes bibliográficas. Por otra parte, hay que señalar que en el título de la mayoría, se hace referencia específica a la técnica del "lavado". Este término se refiere a la aplicación de un color muy diluido en agua y está asociado a la técnica de acuarela y a la aplicación de tintas, normalmente tinta china. Por último, hay que destacar que los tratados de H. Gautier y M. Buchotte, constituyen un referente de los textos escritos en los s. XVII y XVIII sobre materiales y técnicas pictórica (Bordini 1995: 96, 115-116).

Los Cuadernos de apuntes, están asociados a los centros de formación de los ingenieros militares. Se trata de documentos manuscritos de carácter docente, elaborados por los propios alumnos o por profesores de las Academias de Matemáticas, o bien por ingenieros en activo. Contienen recomendaciones y modos de uso de los materiales. Dentro de este grupo, se ha tenido acceso a los siguientes:

Architectura Militar $i$ Civil. Este cuaderno anónimo manuscrito de c.1770 se encuentra en la Fundación Lázaro Galdiano de Madrid ( $\mathrm{n}^{\circ}$ inventario 15010). Contiene breves recomendaciones sobre el uso de los colores, así como el código de color establecido para cada parte de una fortificación.

Apuntes sobre dibujo y arquitectura. El autor de este manuscrito, José Fernández de Olarte fue cadete del Regimiento de Infantería de Saboya, tal como indica en su cuaderno, firmado por él mismo en la ciudad de Barcelona y fechado en 1776. Contiene recomendaciones sobre el uso del color, pinceles, plumas de delineado, etc. En su redacción parece haber tenido una gran influencia el tratado de Buchotte, ya que algunos de sus párrafos coinciden casi literalmente.

\section{Documentos cartográficos del Cuerpo de Ingenieros Militares. Características generales}

Su época de ejecución se enmarca dentro del s. XVIII y principios del XIX. Para su correcta interpretación es necesario conocer su sistema de representación gráfica, el soporte y su adecuada preparación, la realización del dibujo y delineado, la aplicación de los colores y su simbología.

El sistema de representación gráfica más utilizado por los Ingenieros militares era el diédrico, por tanto en sus representaciones se encuentran normalmente plantas, alzados y perfiles y, además, pueden realizarse secciones (Fernández de Medrano 1708). Siempre van acompañados de la correspondiente escala y en todas las ordenanzas del s. XVIII se hace referencia a su uso en la ejecución de mapas y planos, y a las diferentes unidades de medida que se pueden utilizar (leguas españolas, pies de Burgos, leguas francesas, millas de Italia y varas castellanas) [Figura 1]. 
El soporte utilizado era papel hecho a mano a partir de trapos de algodón, lino o cáñamo. El empleado para la cartografía producida por el Cuerpo de Ingenieros era de elevado gramaje, puesto que tenía que ser capaz de soportar la aplicación de la técnica del lavado. Asimismo, sus dimensiones excedían de lo habitual debido a la costumbre de expresar las medidas en pies de Burgos, lo que hacía aumentar el tamaño del dibujo (Burón Castro 2007).

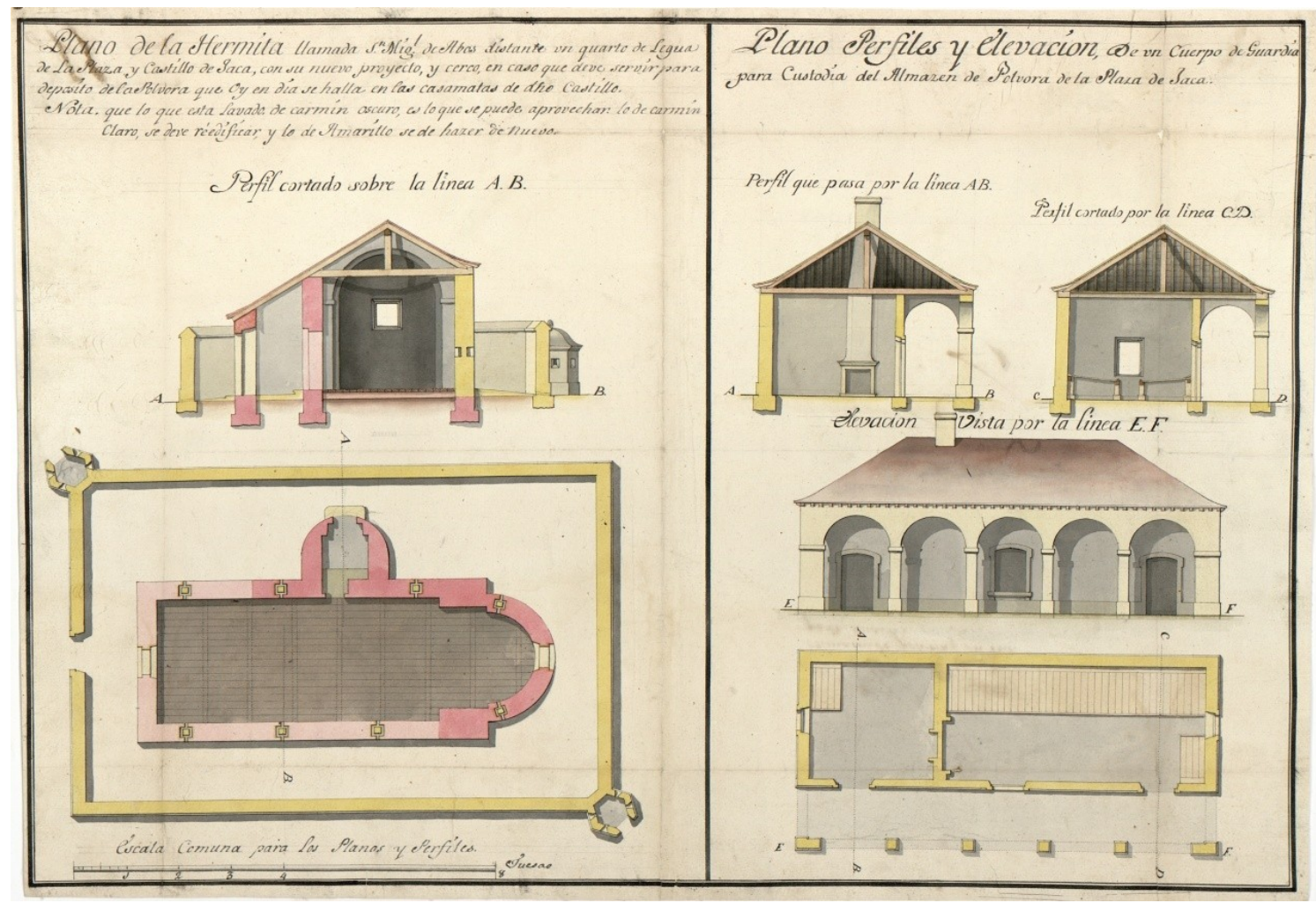

Figura 1. Plantas, perfiles y alzados para la construcción de un almacén de pólvora y de un Cuerpo de Guardia en la plaza de Jaca.

Tamaño del original: 40,5 X 54,8 cm, [Francisco Mauleon], Plano de la ermita de S. Pedro de Abós. Plano, perfiles y elevación de um Cuerpo de Guardia para custodia del Almazen de pólvora de la plaz̧a de Jaca. 1724, Escala: [ca. 1:90]. (España. Ministerio de Defensa. Archivo Cartográfico y de Estudios Geográficos, CEGET)

Cuando un dibujo excedía las dimensiones del papel se unían varios hasta conseguir la dimensión adecuada; para ello se utilizaba como adhesivo cola de boca. Este término deriva de su modo de empleo que es claramente descrito por Fernández de Olarte (1776): "El modo de servirse de esta cola, se hace teniéndola en la boca con los dientes o con los labios y cuando se siente que la saliva está pegajosa se frota con la cola los dos extremos del papel que se quiere pegar, y después, puesto un papel blanco encima del encolado se frota con la uña para que se agarre la cola, y se seque pronto;...". Este mismo autor explica que para su preparación, se pone a hidratar (10 a 12 horas) una cierta cantidad de cola de Flandes², que varía según las recetas, luego se calienta y se añade azúcar blanco. Una vez licuada, se vierte en un plato llano y, antes de que termine de secar, se corta en tiras. Como sustituto de la cola de Flandes se podía utilizar cola de pescado o retazos de pergamino.

Los materiales utilizados para el levantamiento del plano eran: grafito, para la realización de los dibujos, tinta china, para el delineado y repasado de las formas, y tintas de diversos colores, para el lavado del plano.

El uso del lápiz de grafito se hizo habitual en el s. XVII. Inicialmente fue confundido con el plomo, por lo que los términos utilizados para designarlo fueron: mine de plomb, plomb de mer, pierre de mine $\mathrm{y}$ plombagine (todos ellos vocablos franceses). A estos términos hay que añadir la denominación de 
crayon noir, en francés, pénsil, en inglés, y lápiz en español. A finales del s. XVIII Jacques-Nicolás Conté idea un sustituto consistente en una mezcla de polvo de grafito y arcilla, que presionada entre dos semicilindros de madera dio lugar al lápiz moderno.

Hechas estas aclaraciones, hay que indicar que en todos los textos consultados en los que se hace referencia al tipo de lápiz utilizado, se recomienda el uso del lápiz de grafito, nombrado por alguno de los términos anteriores. No obstante, ciertos autores también mencionan otros lápices.

Gautier (1637: 17-21) describe tres tipos de materiales para dibujar. Para los aprendices aconseja el empleo de las ramas carbonizadas de un arbusto, el fufin, es decir, un carboncillo; tiene la ventaja de que se borra fácilmente, simplemente con el extremo de un pañuelo. El otro tipo que recomienda es el plomb de mer, indicando que es mejor el que se suministra cortado en piedra que el que se adquiere en forma de bastón. A este respecto aclara que el segundo está compuesto por pequeñas piezas unidas mediante un adhesivo y que no dura nada. El tercer tipo es el crayon noir o piedra negra del que se sirven principalmente en mampostería y carpintería, pero que no es recomendable para trabajar en papel por ser demasiado duro.

Buchotte (1743: 18) menciona el uso de la piedra de mina de plomo. Se refiere a ella como crayon noir (lápiz negro) o simplemente como pierre de mine (piedra de mina), distinguiendo dos tipos, la fina y la común; respecto a la fina, detalla que existen tres calidades: la muy blanda, la blanda y la dura.

Fernández de Olarte (1776), aunque no hace ningún tipo de aclaración en cuanto a la naturaleza del lápiz, sí recomienda que "no debe ser blando, porque así se rompe a cada instante, ni duro porque hace canales en el papel".

Como el grafito manchaba demasiado se recomendaba el uso de algún sistema de protección. Gautier (1637: 19) menciona el uso de portalápices y Buchotte (1743: 19) aconseja el uso del grafito inserto en bastoncillos de madera.

Por último, D. J. A. y L. (1833: 59) indica que "para afianzar los perfiles del dibujo se emplea el lápiz de piedra" y, además, especifica que bajo esta denominación se refiere a una "especie de esquisto abundante en España, aunque son superiores los lapiceros lígneos de grafito". Respectos a estos últimos advierte que "los mejores son los ingleses de la fábrica Brookman $\mathrm{HB}$ o BB, por ser los más duros y señalar las líneas muy limpias y finas". Por último, añade que como sustitutos se pueden emplear los lápices artificiales franceses de Conté, recomendando los del $\mathrm{n}^{\circ} 3$ para tomar los perfiles de los dibujos. ${ }^{3}$

Tras el dibujado a lápiz se repasaban las líneas con pluma de ave y tinta china. Según Buchotte (1743: 15) las mejores eran las finales del ala derecha y, a este respecto, Fernández de Olarte (1776) especifica que éstas "venian mejor a la mano por coincidir su curvatura con la manera de cogerlas con la mano diestra". En cuanto a sus características también coinciden ambos autores, debían ser las más claras y blandas para facilitar el corte, y preferiblemente viejas; es de suponer que para que estuvieran más secas y firmes. Se preferían las plumas de cuervo para dibujar los paisajes, a las de cisne, más apropiadas para los bordes o cuadros de los dibujos.

Respecto a las acotaciones, notas aclaratorias y firmas, también se hacían con pluma. Podía utilizarse pluma de ave, siguiendo los métodos de dibujo, o bien plumas metálicas, aunque estas últimas empiezan a utilizarse a partir del s. XIX (D. J. A. y L. 1833: 60).

Para la aplicación de los distintos colores se seguía un determinado orden que es especificado por Fernández de Olarte (1776) de la siguiente manera: "se colorea con tinta china, luego lo correspondiente a grandes zonas de agua, después la mampostería, es decir, todo lo que sea edificado, y por último, las zonas verdes". Los materiales utilizados, sus características y preparación se describen en el siguiente apartado. 


\section{Pigmentos y colorantes. Código de colores.}

La técnica utilizada para colorear el dibujo es la del lavado. Se fundamenta en la utilización conjunta del blanco del papel y la transparencia de la capa de color, que permite crear el juego de luces y sombras. Con esta finalidad se usan colorantes y pigmentos de gran transparencia, tales como tinta china, sepia, carmín, gutagamba, verdigrís o ultramar, que una vez ligados con goma arábiga serán disueltos o dispersos en mayor o menor cantidad de agua, consiguiendo de esta manera tonos de distinto grado de saturación (D. J. A. y L. 1833: 111).

El color tiene gran importancia en los documentos cartográficos de los ingenieros militares, puesto que era utilizado como un sistema de transmisión de información. Por esta razón, basándose en las reglas de la arquitectura civil, se establecen unas normas para la utilización de determinados colores según el objeto a representar, su estado físico, el estado de las obras, modificaciones, etc. Todo ello facilitaba el trabajo entre los diversos ingenieros que, a lo largo de un período de tiempo más o menos largo, intervenían en la realización de un determinado proyecto constructivo.

Por tanto, el color se aplicaba atendiendo a un código común para toda la cartografía del cuerpo de ingenieros y arquitectos. Esta forma de proceder supone una gran ventaja que ya reconoce Buchotte de manera expresa: "Parece que la manera de lavar las Obras en la Arquitectura Militar, es más ventajosa, que de la que se sirve la Arquitectura Civil, ya que no se distinguen los Perfiles de lo que se corta o está roto, o con lo que no lo está, si no es en colores o si no están punteados estos lugares" (Buchotte 1743: 41). Este mismo autor especifica los materiales usados para el dibujo y lavado de planos: "Los colores usados ordinariamente para el Dibujo y el lavado de Planos, Cortes, etc., son la tinta de la China; el carmín; el ultramar; la goma-guta; el verd-de-gris líquido, llamado comúnmente, "color de agua"; el bistre; el Indio o indigo; el verde vejiga; el verde iris; el azul de Prusia, y el bermellón” (Buchotte 1743: 1).

Gautier da una relación mucho más amplia de pigmentos y colorantes que clasifica en función de su color (Gautier 1687: 35-37). Para el negro: negro de humo, tinta de la China y tinta común; para el blanco: cerusa; para el violeta: índigo y tornasol; para el amarillo: masicote limón, masicote dorado, oropimente, rejalgar, estil de grana (estil de grain), ocre, azafrán, gutagamba, bayas de espino cerval (grenets de Avignon); para el azul: cenizas azules, índigo muy claro y mezclado con la cerusa, tornasol igualmente mezclado con cerusa y, por último, ultramar; para el rojo: cinabrio preparado, minio, laca de Levante, laca colombina, carmín, bol, sanguina, rojo tostado y la decocción de la madera de Brasil; para el verde: verde destilado, verde vejiga, tierra verde, verdigris molido con vinagre o tártaro; para las sombras: tierra de sombra y bistre. Este mismo autor señala que algunos de estos pigmentos no se usan realmente en la técnica del lavado, sino para corregir defectos o manchas, tal es el caso de la cerusa.

Tal como indica Buchotte, muchos de los pigmentos y colorantes empleados por los ingenieros militares ya se vendían listos para su aplicación (Buchotte 1743: 4). Sin embargo, otros debían ser previamente preparados, con la ayuda de piedras de moler, moletas y cuchillos. En el siglo XVIII, las piedras duras de moler utilizadas en el renacimiento eran consideradas semipreciosas y, por tanto, de coste muy elevado. Por esta razón, fueron sustituidas por otros materiales más accesibles. Habitualmente la piedra de moler era de mármol o de cristal, la moleta era también de cristal, y el cuchillo de acero o hueso, no de madera.

Los colores representados en los documentos cartográficos son: verde, amarillo, carmín, rojo, negro, azul y marrón. Los pigmentos y colorantes aplicados en cada caso, podían variar según el elemento representado. En los siguientes apartados se describen los pigmentos y colorantes utilizados para obtener estos colores. 


\section{Color verde}

Para su obtención se podía emplear: verdigrís, verde destilado, verdigrís molido con vinagre y tártaro, verde de iris, verde vejiga y verdusco oscuro. También podía obtenerse por mezcla de azul y amarillo.

El verdigrís era muy común en las representaciones cartográficas en general y, en particular, en la cartografía de Ingenieros Militares. Con este pigmento se lavaban las áreas de aguas, tales como lagos, ríos y mares, por ser su color muy similar al de las zonas representadas [Figura 2]. Esta estrecha relación queda constatada por una de las denominaciones por las que era conocido "color de agua", y que aparece recogida en muchos de los textos consultados. Aunque en la actualidad este pigmento ya no se utiliza, hasta el s. XIX, tuvo una gran importancia. Es de origen sintético y se obtiene mediante la corrosión del cobre provocada por la acción del ácido acético contenido en el vinagre, aunque también se puede formar por la acción de cloruros (cloruro sódico o cloruro amónico). Esta diversidad de procesos corrosivos es responsable de que la composición del pigmento pueda variar. Por ejemplo, ha sido identificado como un acetato de cobre (II) hidratado $\left[\mathrm{Cu}\left(\mathrm{CH}_{3} \mathrm{COO}\right)_{2} \cdot \mathrm{H}_{2} \mathrm{O}\right]$, un hidroxiacetato de cobre (II) hidratado $\left[\mathrm{Cu}_{\mathrm{x}}\left(\mathrm{CH}_{3} \mathrm{COO}\right)_{\mathrm{y}}(\mathrm{OH})_{\mathrm{z}} \cdot \mathrm{nH} 2 \mathrm{O}\right]$ o un hidroxicloruro de cobre (II) $\left[\mathrm{Cu}_{\mathrm{x}} \mathrm{Cl}_{\mathrm{y}}(\mathrm{OH})_{\mathrm{y}} \cdot \mathrm{nH}_{2} \mathrm{O}\right]$ ( $\mathrm{Kühn} \mathrm{1993;} \mathrm{Scott} \mathrm{et} \mathrm{al.} \mathrm{2001;} \mathrm{Santos} \mathrm{et} \mathrm{al.}$ 2002; Santos et al. 2003). Estas diferencias son responsables de que su color varíe, pudiendo ser verde, verde - azulado o incluso azul (De la Roja et al. 2007).

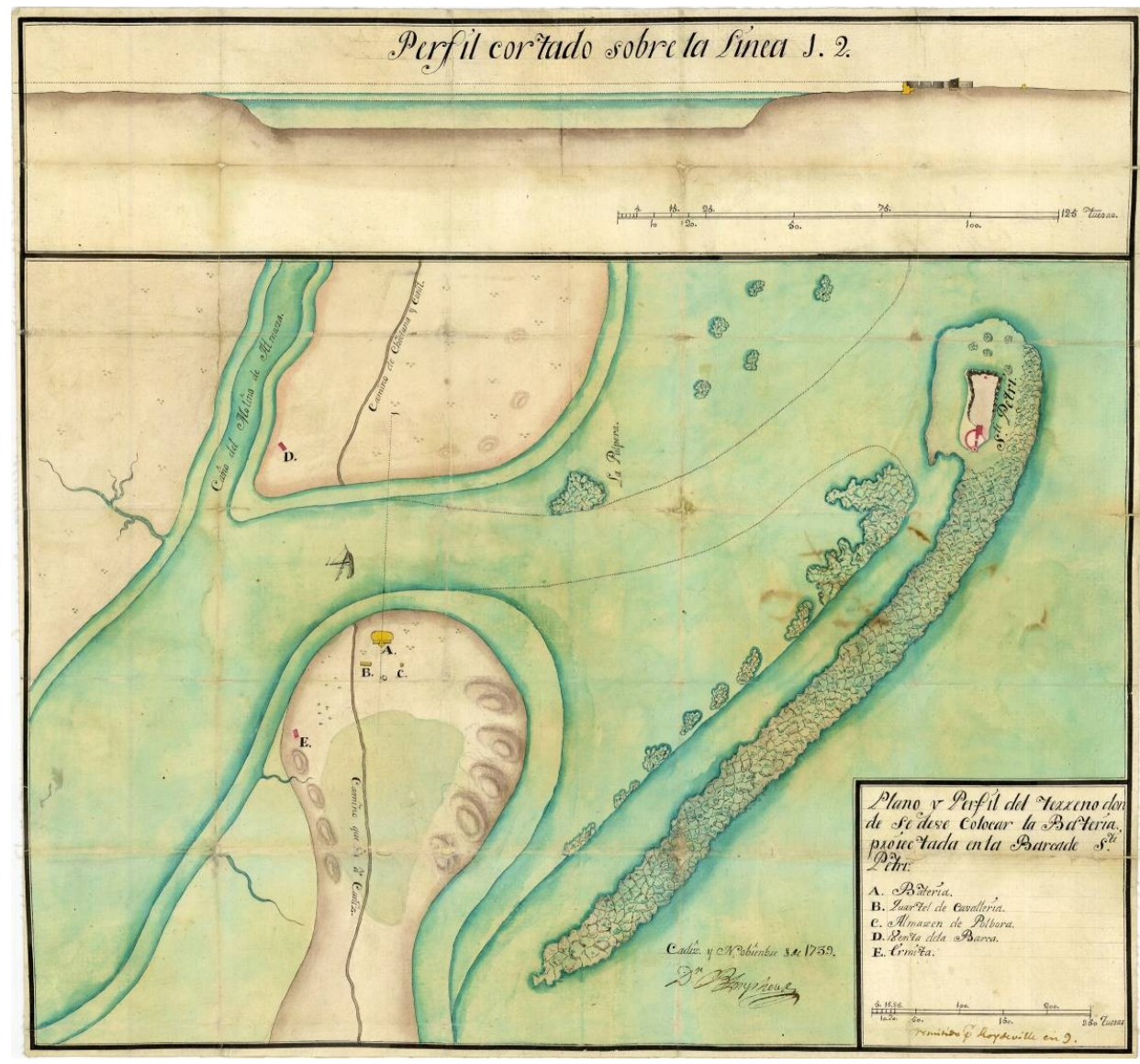

Figura 2. Área de color verde-azulado que muestra el supuesto "color de agua": verdigrís.

Tamaño del original: 48 X 51cm, B. Amphoux, Plano y perfil del terreno que se desea colocar la Bateria proiectada en la Barca de Sti. Petri. 1739, Escala: [ca. 1:5.000]. (España. Ministerio de Defensa. Archivo Cartográfico y de Estudios Geográficos, CEGET). 
Uno de sus usos tradicionales ha estado relacionado con la elaboración de tintas. Algunas de las recetas referidas a su preparación, están relacionadas con su empleo en cartografía para la representación de zonas de agua, e incluso en ciertos casos se especifican las características que el pigmento debe tener para este uso. Por ejemplo, en el tratado anónimo del s. XIX estudiado por Hidalgo, se indica que el verde de gris líquido o color de agua debe tener un color azul celeste (Hidalgo 1980). En este caso bajo la denominación de color de agua se está refiriendo a la variedad básica de verdigrís que presenta una tonalidad azulada (San Andrés et al. 2009).

Gautier describe el verde destilado. La lectura de su receta de preparación lleva a la conclusión de que en realidad se trata de una variante del verdigrís, conocida como verdigrís purificado o destilado. Según este autor se prepara a partir de verdigrís que se mezcla con vinagre y tártaro, "obteniéndose un color muy bello". Dentro del mismo apartado dedicado a los colores verdes, incluye la preparación del verdigrís molido con vinagre y tártaro $\mathrm{y}$, al igual que en el caso anterior, especifica que "se obtiene un hermoso color verde que se volverá más hermoso cuanto más se deje envejecer" (Gautier 1687: 53-54).

Para la representación del verde de la vegetación y zonas de la campiña se empleaban extractos vegetales, es decir, colorantes: verde vejiga, verde de iris y verdusco oscuro o verde de yezgo.

Según Fernández de Olarte (1776) y Buchotte (1743: 13), el verde vejiga es el color que usaban los ingenieros militares para las zonas de vegetación, tales como, viñas, jardines y valles. La denominación de verde vejiga, sinónimo de verde sapo, toma su nombre de las vejigas, de cerdo o cordero, en las que se dejaba secar tras su preparación. El colorante se obtiene de las bayas maduras del espino cerval, arbusto que se conoce como "persian berries" en inglés y "graines d'Avignon" en francés. Pertenece al género Rhamnus y a la familia de las Rhamnaceas, y el colorante, extraído presionando las bayas, pertenece al grupo de los colorantes flavonoides. Su principal componente es la rhamnetina (rhamnetin), junto con la quercetina (quercetin) y el kaemferol (kaempferol) (Cardon 2003:157-158; Hofenk de Graaf 2004:194-201). Este colorante puede ser utilizado como tinte o bien puede ser precipitado con alumbre y/o cal y ser empleado como laca (Eastaugh et al. 2004: 384; Gettens y Stout 1966: 154).

Ni Fernández de Olarte ni Buchotte son muy explícitos en cuanto a su preparación, y únicamente indican que se machacan las bayas y el jugo extraído se almacena en vejigas, sin añadir goma arábiga a la mezcla, pues según el primero, "el verde vejiga contiene su propia goma". Sin embargo, Gautier, además de mencionar que se extrae del fruto del Rhamnus, indica que se le añade alumbre y después se guarda en una vejiga donde se deja secar; por tanto, este autor se está refiriendo a la preparación de una laca. Además, explica que para su aplicación, primero se muele sobre un mármol y después se pone en un cubilete o en una concha (Gautier 1687: 52-53).

El verde de iris es un colorante que se extrae de los pétalos del lirio, también conocida como flor de iris. Todos los textos describen un proceso similar. Se toman los pétalos más azules se trituran en un mortero de mármol, se añade polvo de alumbre y un poco de cal en polvo; se extrae el jugo y se deja secar en un cubilete. Concretamente, este es el proceso descrito por Buchotte (1743: 13), que es muy parecido al explicado por Fernández de Olarte (1776). En el apartado que Gautier y el autor del texto editado por Ballard dedican a la preparación del verde de iris, describen un método semejante, sin embargo, en este caso la adición de cal, de la que especifican es cal viva, es opcional y únicamente la recomiendan para obtener un verde más vivo. Por último, ambos autores señalan que para obtener un verde diferente se debe partir de flores de color violeta, aunque, según se especifica en el texto anónimo, el verde nunca será tan vivo (Gautier 1687: 53; Ballard 1697: 227 229). Según Fernández de Olarte (1776), el verde de iris "se vende en conchas. Este verde es más hermoso y alegre que el de Vejiga, pero sirve para lo mismo". Además, indica que al igual que el de vejiga, "el Verde Iris tiene también su goma".

Hay que indicar que D. J. A. y L. menciona también el uso del verde vejiga y el verde iris. Sin embargo, comenta que si bien el primero fue muy apreciado en épocas anteriores "su uso es totalmente 
desaconsejable pues es un color falso y su tinta tiene una crudeza insoportable". Asimismo, especifica que el verde de iris es aún más fugaz que el verde vejiga (D. J. A. y L. 1833: 15).

El texto editado por Ballard ofrece la receta de otro color verde al que llama verdusco oscuro, que no mencionan los otros autores, y que puede ser debido a que no era utilizado en el lavado de la arquitectura militar. A este respecto hay que señalar que este color es mencionado dentro de las recomendaciones referidas a los fondos de los retratos hechos en miniatura y para el lavado en papel (Ballard 1697: 343-244). La planta de la que se extraía este color es el yezgo (Sambucus ebulus), planta herbácea de cuyos frutos maduros se puede obtener un tinte verdoso (Cardon 2003: 202203). Según se describe en este texto, los frutos o bayas se dejan en una bodega durante seis o siete días hasta que se pudran, después se exprimen y el jugo se filtra con una tela y, finalmente, se mezcla con agua de alumbre. No es necesario añadir goma. El líquido obtenido se almacena en un cortadillo ${ }^{4}$ de vidrio o de loza y se mantiene aireado, pero protegido del sol. De esta manera está disponible para el lavado, proporcionando un colorido verdusco y oscuro.

Por último, Gautier (1687: 53) es el único que menciona el uso de la tierra verde mezclada con agua gomada.

Como se ha indicado al principio de este apartado, el color verde también se puede obtener por mezcla de los colores azul y amarillo. En el tratado estudiado por Hidalgo se especifica que para representar las áreas de vegetación se usan mezclas de colores azul y amarillo: "azul y amarillo hacen verde y asi el indio o añol o color de agua con la gutagamba hacen un buen verde" (Hidalgo 1980). Las denominaciones de indio o añol (sic) hacen referencia al índigo, aunque la segunda también puede tener relación con el glasto.

D. J. A. y L. hace referencia a la mezcla de azul de Prusia, azul ultramar o azul de cobalto, con gutagamba. También menciona la mezcla de azul añil y piedra de hiel. En todos los casos indica que variando las proporciones de ambos pigmentos, o incluso añadiendo tinta china, sepia, tierra de siena quemada o laca, se puede conseguir una amplia gama de tonalidades, lo que permite representar todos los verdes de la naturaleza (D. J. A. y L. 1833: 114-115). Según explica este mismo autor, el término de piedra de biel se refiere a una concreción que se encuentra en la vejiga de la hiel de buey y de la que se extrae un color amarillo intenso que se utiliza para la aguada (D. J. A. y L. 1833: 22-23).

\section{Color amarillo}

Con este color se lavaban las partes proyectadas de una obra y todavía no construidas [Figura 3]. Principalmente se utilizaba la goma guta o gutagamba. Según Buchotte (1743: 3-4): "La goma-guta es una goma resinosa, que viene de la Indias, en trozos bastante gruesos, a menudo en barras duras pero quebradizas, extremadamente amarilla. Viene de Siam ${ }^{5}$, de la provincia llamada Cambaudia 6 , vecina del Reino de la China". Asimismo, Fernández de Olarte (1776) añade: "sirve para lavar los proyectos, y obras que se hacen para un sitio, como las trincheras, etc.".

Se trata de una sustancia resinosa extraída de diferentes árboles del género Garnicia, siendo el más importante el Garnicia hanburyi. Se obtiene practicando cortes alrededor del tronco y era recogida en cañas de bambú. En su estado natural, es una resina de color marrón amarillento, que va tomando un color amarillo brillante conforme se va secando y este tono se intensifica al ser pulverizada. Su principal componente es el ácido gambógico (Winter 1997).

Gautier, además de la goma guta, describe otros colorantes: azafrán y estil de grana (Gautier 1687: 4647). El primero se extrae de los estigmas de la flor del azafrán (Crocus sativus) y su principal principio colorante es la crocetina (Hofenk de Graaf 2004: 202-207). Según este autor, para su aplicación se disuelve con agua gomada; el color obtenido "es bello al principio, pero no da buen resultado porque se 
empaña”. El estil de grana se obtiene a partir de las bayas verdes del espino cerval (Eastaugh et al. 2004: 353). Se conoce también como grana de Avignón y así lo nombra Gautier. Su proceso de elaboración es similar al descrito para el verde vejiga, si bien en este último caso se parte de las bayas maduras del fruto del Rhamnus. Este mismo autor indica que se puede diluir con un poco de agua de goma. También apunta que se puede mezclar con cerusa; para ello, especifica que el pigmento se muele finamente y después se mezcla con el líquido resultante de la cocción de las bayas de la grana de Avignon.
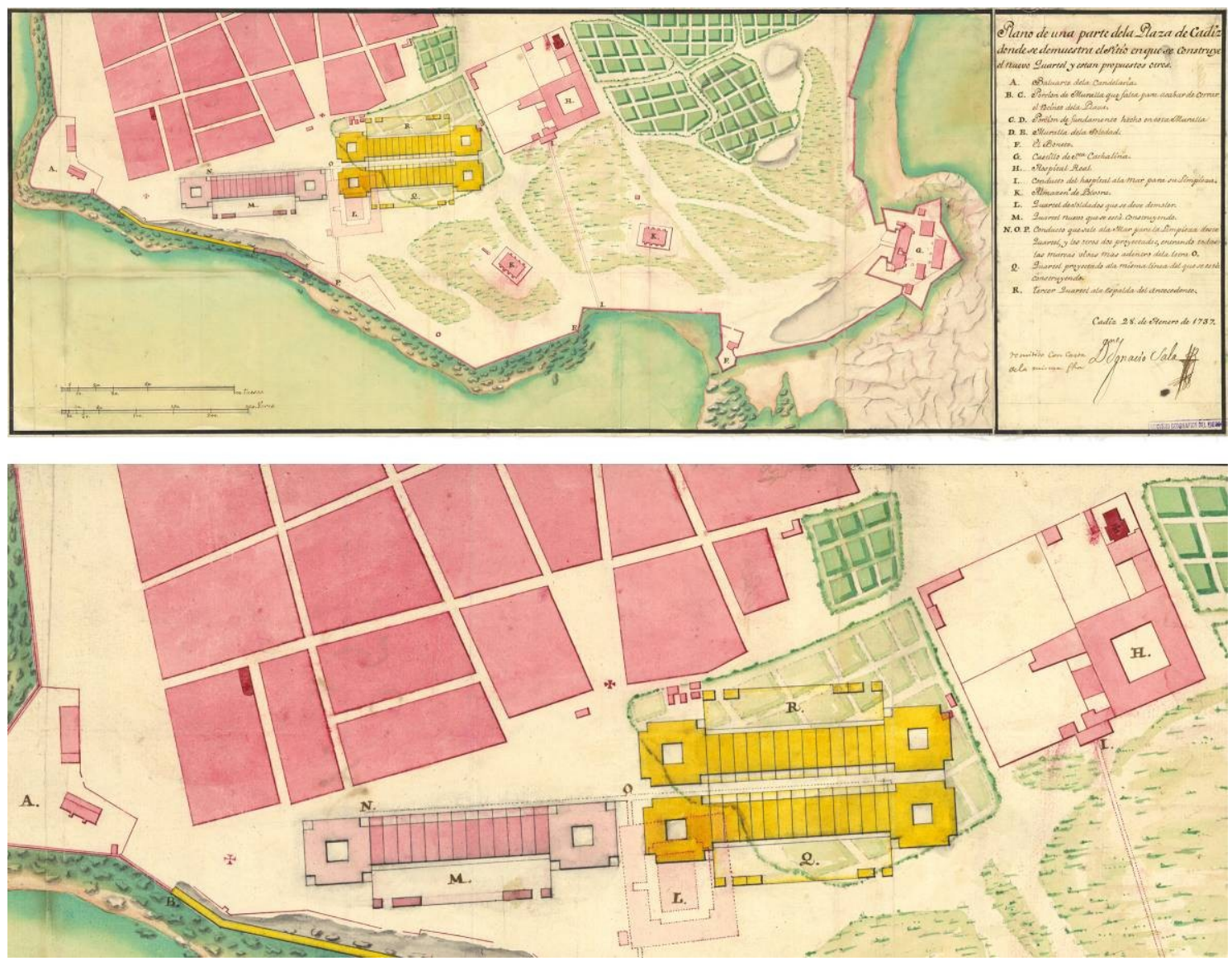

Figura 3. Plano parcial de población de la ciudad de Cádiz lavado en diferentes tonalidades (Imag. superior). Detalle de la utilización del color carmín para la representación de las zonas construidas y del amarillo para las zonas proyectadas en el núcleo de población (Imag. inferior).

Tamaño del original: 33 X $94 \mathrm{~cm}$, Tamaño del detalle: 17,6 X 42,9 cm, Ignacio Sala, Plano de una parte de la Plaza de Cádiz. donde se demuestra el sitio en que se construye el nuevo Cuartel y estan propuesto otros. 1737, Escala: [ca. 1:1.5000]. (España. Ministerio de Defensa. Archivo Cartográfico y de Estudios Geográficos, CEGET).

Gautier menciona otros pigmentos amarillos (oropimente, rejalgar, masicote amarillo y dorado, y ocre), que no son incluidos en la relación de materiales dada por los otros autores, a excepción de D. J. A. y L. que describe su uso junto con el del amarillo de Nápoles y amarillo de cromo. Ambos autores advierten sobre el carácter venenoso del oropimente y el rejalgar.

\section{Color carmín}

Se utilizaba para lavar las zonas existentes de una fortificación y las partes que iban a ser derribadas, según que la línea fuera continua o punteada [Figura 3]. En todos los textos se hacen ciertas consideraciones respecto a sus características; por ejemplo, se indica que debe ser un color de tonalidad intensa, más rojo que granate, y formar un líquido homogéneo al ser mezclado con goma 
arábiga. Sin embargo, únicamente Gautier y el autor del texto editado por Ballard aportan datos relacionados con su naturaleza. Ambos hacen referencia al uso de dos tipos de colorantes: la cochinilla, de origen animal y el palo de Brasil, de origen vegetal.

Gautier dedica un apartado a la preparación de las lacas de Levante, de Venecia y Colombina y otro a la del carmin (Gautier 1687: 49-51). Para la obtención de las dos primeras, se parte de una mezcla de palo de Brasil y cochinilla que junto con terra mérita, alumbre calcinado y hueso de jibia, todos ellos en polvo, se hierven con lejía hasta obtener un color muy intenso; después se añade alumbre calcinado, se filtra y deja secar. Respecto a la laca Colombina, especifica que se utiliza vinagre, en lugar de lejía, y el colorante empleado es únicamente palo de Brasil, que debe mantenerse en vinagre durante un mes; transcurrido este tiempo se añaden los restantes componentes indicados anteriormente. Para la preparación del carmín se parte de carmín de cochinilla que se moltura con granos de Cohan y racourt. Esta mezcla se hierve con agua corriente hasta que adquiere una fuerte coloración, después se añade un poco de alumbre de roca, se filtra y se deja secar.

En relación a los aditivos mencionados, el término de terra mérita se utilizaba en el siglo XVIII como sinónimo de cúrcuma, colorante amarillo que se extrae de la raíz de la cúrcuma longa o azafrán de la India, planta herbácea de la familia de las zingiberáceas. Sus principios colorantes pertenecen al grupo de los curcuminoides y se utiliza principalmente como especia por su aroma y color. Además, se ha empleado con tinte y, en algunos casos, como aditivo del colorante del quermes para avivar su color (Hernández de Gregorio 1803: 125; Cardon 2003: 247-249; Hofenk de Graaf 2004: 56). Tradicionalmente, el alumbre, ha sido muy utilizado como mordiente de colorantes en técnicas de tinción de tejidos; igualmente, ha sido muy empleado como sustrato para la elaboración de lacas. Es un sulfato doble de aluminio y potasio que se encuentra en la naturaleza en forma de alunita $\left[\mathrm{KAl}_{3}(\mathrm{OH})_{6}\left(\mathrm{SO}_{4}\right)_{2}\right]$. Cuando se calienta por encima de $100^{\circ} \mathrm{C}$ se deshidrata obteniéndose el alumbre calcinado. Por último, el bueso de jibia, como su nombre indica es el hueso o concha de la jibia o sepia, molusco que pertenece al orden de los cefalópodos. Es rico en carbonato cálcico $\left(\mathrm{CaCO}_{3}\right)$ por lo que ha sido utilizado en la elaboración de lacas. Hay que señalar que, de momento, no se ha podido determinar el significado de Cohan y racourt, aunque el primero se supone que se refiere a una flor.

Las recetas recogidas en el texto editado por Ballard (1697: 226-229) son bastantes similares a las descritas por Gautier. En una de ellas explica la preparación del "carmín con poco gasto", indicando que se parte de palo de Brasil, al que denomina "bresix de Fernambourg", que se mezcla con vinagre destilado y se deja durante veinticuatro horas, después se hierve y filtra. Al líquido obtenido se le añade alumbre de roca en polvo, es decir alumbre natural, y vinagre blanco, se agita y la espuma resultante se recoge y deja secar. La otra receta se refiere, simplemente, a "otro secreto para hacer carmín"; en este caso se parte de carmín que se añade a una mezcla, previamente hervida, de agua corriente y semilla de Cohan. A esta disolución se le añade racourt y nuevamente se hierve, después se añade alumbre de roca. El líquido se filtra y distribuye en varios recipientes de cristal. Se deja reposar y evaporar el agua. El sólido se recoge, se deja secar y se pasa por un tamiz. Dependiendo de la cantidad de rocourt el producto será más rojo o más carmesí.

Gautier (1687) también menciona el palo de Brasil mezclado con cochinilla y agua y sin ningún otro aditivo; por tanto, en este caso se refiere a la preparación de un tinte (Gautier 1687: 52).

El término de carmín se asigna al colorante extraído de la cochinilla (Dactylopius coccus antiguamente conocido como Coccus cacto) o del quermes (Kermes vermilio). A partir del s. XVI se intensifica el uso del primero, procedente de América y cuya producción y comercio fue monopolizado por España (Bruquetas 2000: 125). La hembra de ambos insectos proporciona un colorante de color rojo carmesí y sus principales componentes son los ácidos quermésico y flavoquermésico. El colorante se extraía machacando el insecto seco y tratándolo con lejía. Fueron muy valorados en tintorería y en la elaboración de lacas rojas (Schweppe y Roosen-Runge 1986). 
Bajo la denominación de palo del Brasil se incluyen diferentes colorantes extraídos de las conocidas como maderas rojas solubles, pertenecientes a la especie Caesalpina. El verdadero palo del Brasil procede del árbol Caesalpina brą̧ilensis, aunque existen otras variedades, entre las que se destaca la madera de Pernambuco o Fernambuco. El principal componente de este colorante es la brasilina (Báez y San Andrés 1999).

Además de estos colorantes, los ingenieros militares utilizaban el bermellón ( $\mathrm{HgS})$ para lavar las cubiertas de teja. Este término se refiere al sulfuro de mercurio (II) de origen artificial. Sin embargo, también ha sido asignado al mineral cinabrio $(\mathrm{HgS})$ purificado mediante sublimación (D. J. A. y L., 1833: 14). En los tratados consultados no se menciona su forma de uso, sólo se dice la utilidad que recibía, de lo que se deduce que no era tan empleado como el carmín. Hay que señalar que Gautier hace referencia al empleo del cinabrio, del que dice que es un mineral que se vende preparado o en piedra; en este segundo caso se debe moler con orina, con la que se lava hasta cuatro veces; después se decanta y se deja secar. Para su aplicación, se mezcla con agua de goma con la que se moltura (Gautier 1687: 48-49).

Otros pigmentos de color rojo mencionados por Gautier son: minio, sanguina y rojo tostado (Gautier 1687: 49, 52). El minio $\left(\mathrm{Pb}_{3} \mathrm{O}_{4}\right)$ es un pigmento de color rojo-naranja que se obtiene por tostación del blanco de plomo o cerusa. La sanguina se suministra en forma de minas o barritas y se prepara a partir de pigmento ocre rojo. La designación de rojo tostado presumiblemente hace referencia a una tierra roja tostada.

\section{Color negro}

Con él se delineaban y repasaban los contornos de las formas que, posteriormente, serían lavadas con color ; igualmente es utilizado para la redacción de textos o leyendas explicativas, firma de autor y escalas gráficas. En el primer caso se suele utilizar la tinta china [Figura 4] o tinta metaloácida [Figura 5].

La tinta china se prepara a partir de negro de humo u hollín, que es carbón finamente dividido. Antiguamente, se obtenía rascando las piedras del fogón, la base de los calderos o las paredes del horno. Posteriormente, se empezó a producir mediante combustion incompleta de madera resinosa, aceites vegetales o grasas animales, haciendo pasar el humo por paredes frías o por una chimenea para facilitar la precipitación del carbono. El pigmento así obtenido se mezcla con un aglutinante (cola de pescado), se perfuma con almizcle o alcanfor y, finalmente, se moldea en barritas que se dejan secar (Gettens y Stout 1966: 105). Para su empleo, la barra se frota sobre una superficie rugosa en la que previamente se vierte un poco de agua. En el s. XVIII, la tinta china se compraba en barritas ya listas para su uso. No obstante, Fernández de Olarte (1776) incluye una receta para su elaboración, partiendo de huesos de melocotón calcinados. Obviamante, el color de la tinta china era negro, aunque según Fernández de Olarte (1776) y Buchotte (1743: 2) debía tener un tono cálido.

La tinta metaloácida, concretamente ferrogálica, era utilizada, ocasionalmente, para las notas y, normalmente, para las firmas. A esta hipótesis se llega tras observar el comportamiento de las propias tintas: mientras que en la tinta china el color permanece estable, en las ácidas, se observa que tiende a marronáceo y este cambio va acompañado de una degradación del papel.

En el texto anónimo editado por Ballard, se hace referencia a este tipo de tinta como "una muy buena tinta para dibujar y escribir" preparada a partir de agallas de roble ("noix de galle") (Ballard 1697: 220). Las agallas son excrecencias esféricas que aparecen en la región cambial de los brotes jóvenes del roble, y que son generadas por la puesta de huevos de diversos insectos himenópteros de la familia Cynips. Contienen taninos, especialmente ácido gálico, que se extraen cociendo las agallas en agua. Las tintas ferrogálicas se obtienen añadiendo sulfato ferroso $\left(\mathrm{FeSO}_{4}\right)$ que reacciona con el ácido 
gálico, formando galonatoferroso que posteriormente se oxida a galonatoférrico de color negro. Para su aplicación se utiliza mezclado con goma arábiga que actúa como aglutinante.

Además de las tintas anteriores, Gautier también menciona el negro de bumo (Gautier 1687: 37-38) especificando que se obtiene quemando colofonia. Se puede utilizar mezclado con agua de goma y se aplica con pincel. También sirve para dibujar; en este caso se mezcla con algodón que se habrá molido con tinta común (con esta última denominación Gautier se refiere a la tinta metaloácida).

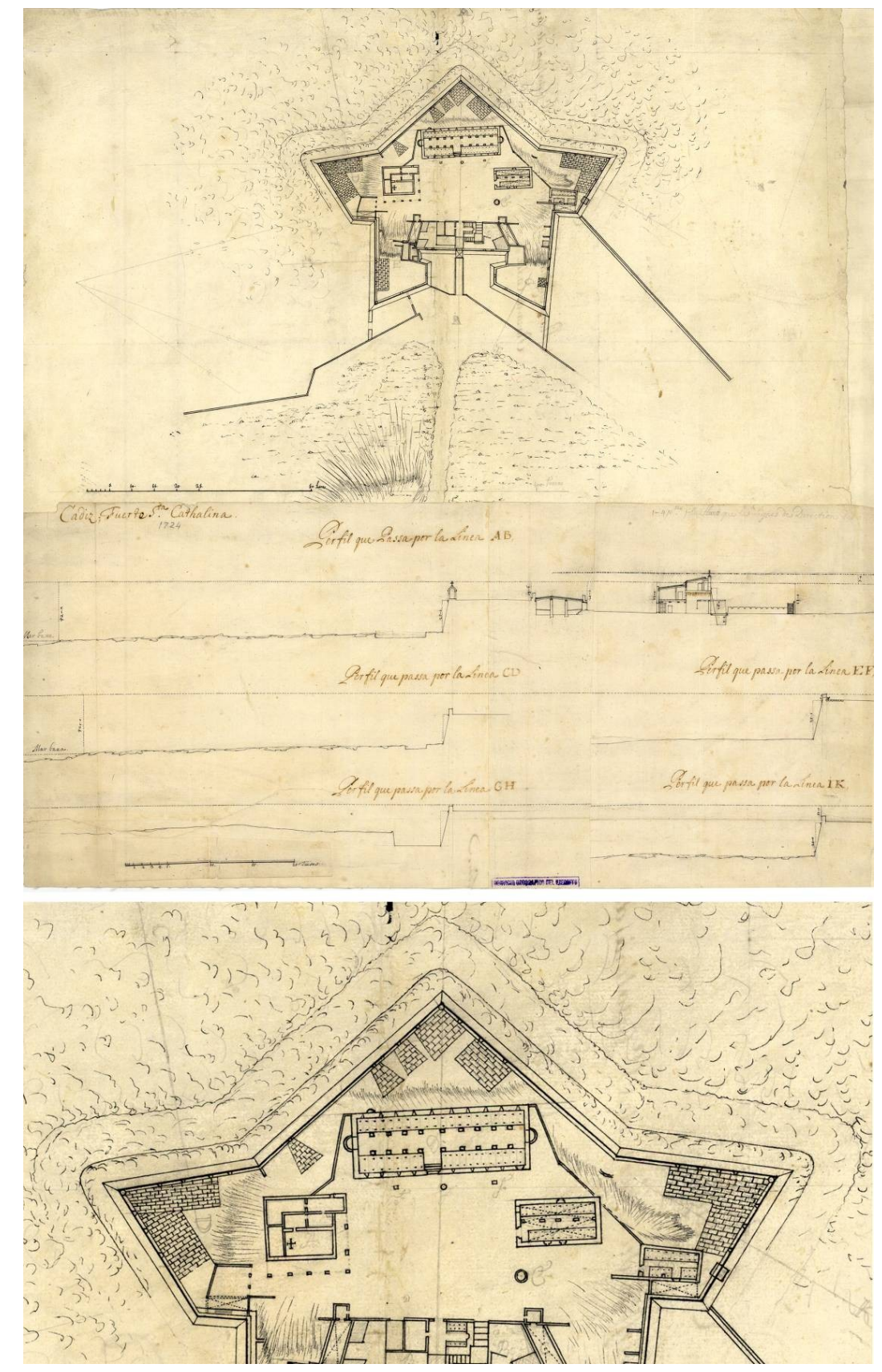

Figura 4. Dibujo realizado con lápiz y tinta metaloácida, y delineado, supuestamente, con tinta china (Imag. superior). Detalle de área de fortificación delineada con tinta china (Imag. inferior)

Tamaño del original: 63 X 61 cm, Tamaño del detalle: 14, 5 X 27,8 cm; Ingenieros Militares, Cádiæ. Fuerte de Sta. Cathalina. Ingenieros Militares, 1724, Escala: [ca. 1:600]. (España. Ministerio de Defensa. Archivo Cartográfico y de Estudios Geográficos, CEGET). 

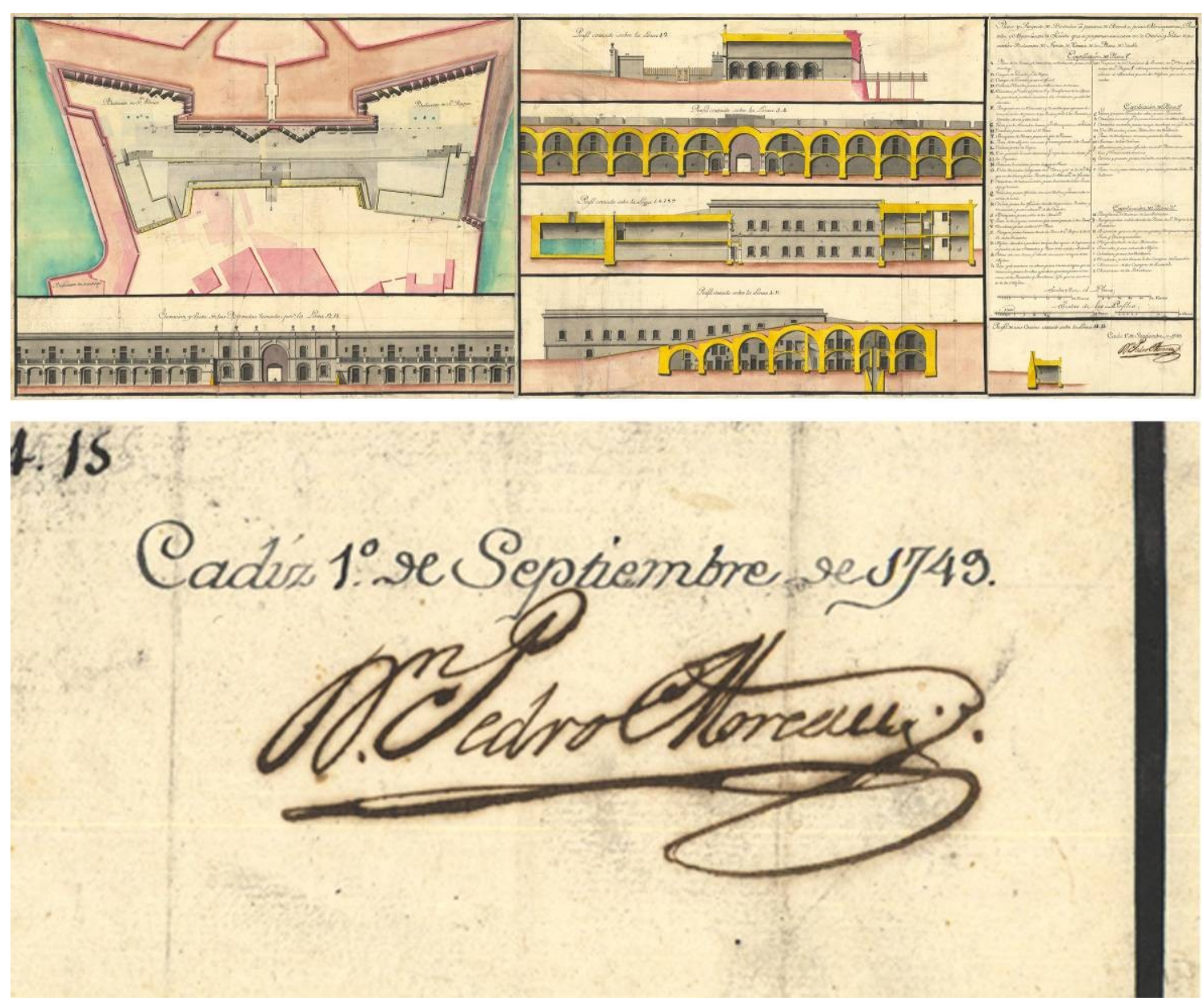

Figura 5. Plano coloreado (Imag. superior) y detalle ampliado del área de la firma supuestamente realizada con tinta metaloácida. Obsérvense sus características diferentes respecto a la empleada para anotar la fecha de datación y el reborde del documento (Imag. inferior).

Tamaño del original: 53 X 163,3 cm, Tamaño del detalle: 7,1 X 13,2 cm; Pedro Moreau, Plano y Proyecto de Bovedas a prueba de Bombas para Almazenes, Quarteles y Alojamientos de Oficiales que se proponen edificar en la Cortina y Golas de los medios Baluartes del Frente de Tierra de l a Plaza de Cádiz: 1749, Escala: [ca. 1:600]. (España. Ministerio de Defensa. Archivo Cartográfico y de Estudios Geográficos, CEGET).

\section{Color azul}

Su uso se limita a cartelas decorativas o al lavado de pequeñas áreas que representan elementos constructivos, tales como metales o vidrio, u objetos elaborados con alguno de estos materiales [Figura 6]. A este respecto, en el tratado anónimo estudiado por Hidalgo, se indica lo siguiente: "Azuly negro bacen un color oscuro aturquesado por lo que toca el indio o color de agua con muy poca tinta de china da un color propio para lavar las sombras de hierro, plomo, pizarra y vidrio, haciendo la tinta para el hierro más oscura que para la pizarra, para el plomo menos azul y más clara y para el vidrio muy clara" (Hidalgo 1980).

Según lo anterior, se pueden emplear dos tipos de azules: el azul indio, es decir, el indigo y el color de agua, es decir, el verdigrís básico, variedad de verdigrís de color azulado. Otros pigmentos que mencionan los textos consultados son el azul ultramar y el ažl de Prusia. Así como en el caso del índigo y el verdigrís básico, se especifica su empleo para lavar zonas de pizarra, hierro, plomo y vidrio; en el caso de los otros pigmentos, no se indica en qué zonas se aplicaban. 
El índigo es una sustancia colorante extraída de la Indigofera tinctoria, planta originaria de la zona del Indo y cultivada desde la antigüedad. Fernández de Olarte (1776) aclara que fue utilizado por los ingenieros militares para "lavar todo lo que ha de ser de vidrio, bierro, etc según las diferentes tintas; y no es fácil de emplear". Se podía comprar en forma de pequeñas barritas en las droguerías de París, tal como señala Buchotte (1743: 5).

$\mathrm{El}$ azul de Prusia es un ferrocianuro férrico, $\mathrm{Fe}_{4}\left[\mathrm{Fe}(\mathrm{CN})_{6}\right]$, sintetizado por primera vez en 1704 por Diesbasch (fabricante de colores) y Dippel (químico). Buchotte (1743: 3) y Fernández de Olarte (1776) lo describen como "una especie de piedra friable; este color es muy aproximado al Indio, o indigo, pero no tan bello. Para usarlo en el Lavado y en la miniatura, se hace la molienda en un mármol bien fino, y en seco; por lo demás, este color no es tan fácil de usar en el lavado, como el Indio, y el ultramar".

El pigmento azul ultramar tiene su origen en una piedra semipreciosa conocida como lapislázuli, por la que también se conoce como az̧ul lapislázuli. En el s. XIX alcanzó unos precios prohibitivos y en 1828 Jean Baptiste Guimet logra obtenerlo de forma sintética (Eastaugh et al. 2004: 375-376). Por tanto, Buchotte y Fernández de Olarte al nombrar el ultramar se refieren al de origen natural.

D. J. A. y L. (1833: 25) menciona otro pigmento azul de origen sintético, el azul de cobalto $\left(\mathrm{CoO} \cdot \mathrm{Al}_{2} \mathrm{O}_{3}\right)$ que fue obtenido por Louis-Jacques Thénard en 1802.

\section{Color marrón}

Para su obtención se puede utilizar bistre, extracto de regaliza y tierra de sombra. En la arquitectura civil y militar eran utilizados para lavar las zonas correspondientes a la madera: carpinterías, estructuras... [Figura 6]. El bistre fue un color muy usado en acuarela durante el siglo XVIII. Se preparaba con cenizas de madera calcinada; el de mejor calidad era el de madera de haya (Harley 1982: 154-155). Según describe Buchotte, "una vez recogidas las cenizas, se hervían para que soltaran bien el color y, después, se filtraba con la ayuda de un papel, preferiblemente en frío, ya que en caliente las fibras del papel se dilatan y pueden pasar impurezas" (Buchotte 1743: 12). Se vendía seco o líquido y su precio era asequible.

El extracto de regaliza u orusus es mencionado en el tratado anónimo estudiado por Hidalgo (1980). Se disuelve en agua goma y tiene el color de la madera por lo que se utiliza para lavar las obras de carpintería, fosos y el color de tierra en general. Se extrae de la raíz de la planta de regaliz (Glycyrrbiza glabra).

\section{Recomendaciones en el uso de los pigmentos y colorantes}

En los textos relacionados con la técnica del lavado, además de explicar la forma de proceder con esta técnica y describir los pigmentos y colorantes utilizados, también se dan instrucciones relacionadas con su mezcla para obtener ciertos colores. Algunas de estas cuestiones ya han sido descritas en los apartados anteriores y otras se comentan a continuación.

Uno de los primeros aspectos a considerar se refiere a su molienda, que debía ser buena para evitar grumos en el momento de su aplicación en el papel, ya que la aguada y el lavado no son técnicas pictóricas matéricas, sino que están basadas en la transparencias de las capas. 

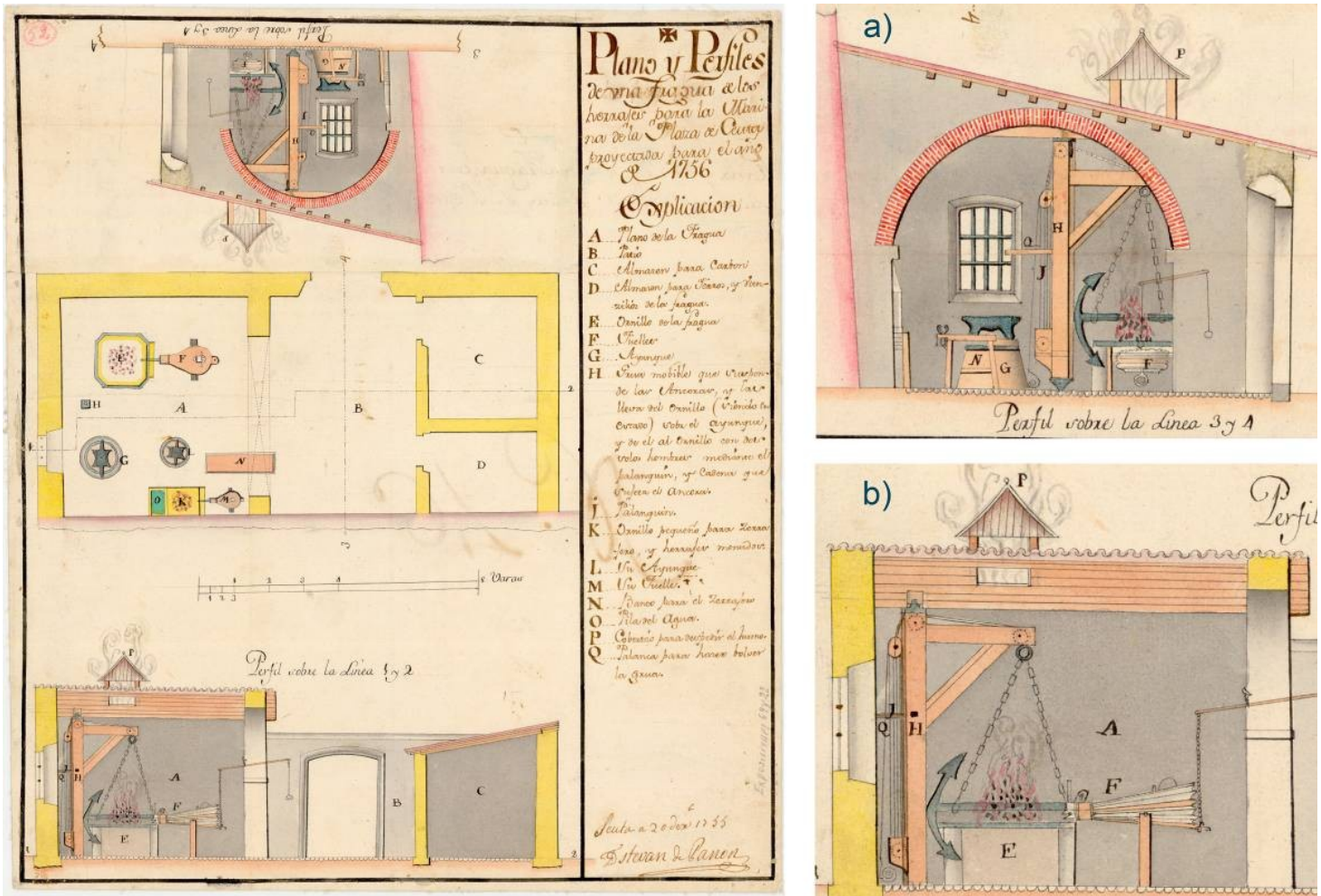

Figura 6. La imagen muestra el plano y perfiles de una fragua (Imag. izquierda). En los detalles ampliados a) y b), se puede observar la utilización del color marrón para la representación de los elementos constructivos de la fragua, que son de madera, y el color azul-gris para los objetos metálicos, en este caso el ancla y el yunque (Imags. derecha).

Tamaño del original: 35 X $31 \mathrm{~cm}$, Tamaño del detalle a): 9,5 X 11,4 cm, Tamaño del detalle b): 9,3 X 9,8 cm, Estevan de Panon, Plano y Perfiles de una fragua de los herajes para la Marina de la Plaza de Ceuta proyectada para el año 1756., 1755, Escala: [ca. 1:60], Ceuta. (España. Ministerio de Defensa. Archivo Cartográfico y de Estudios Geográficos, CEGET).

Algunas recomendaciones sobre la utilización de los pigmentos eran detalladas, sobre todo las referidas al modo de diluir los colores en agua o en "agua engomada"; sin embargo, en otros casos eran muy escuetas. Tal es el caso del texto anónimo de 1770, que dentro del apartado titulado "De la composición de los colores", da las siguientes indicaciones: Negro: .. La Tinta de la China que se deshace con agua. Colorado... El Carmin, tambien con agua, y goma Arabiga. Pagiso... La Gutagamba, igualmente con agua. Verde... El de Bexiga, se mezcla con color de agua y tambien mezclando la última con Gutagamba. Hierro... Añil con agua y goma. Azul... El de Prussia, idem. Morado... Azul mezclado con Carmin” (Anónimo 1770).

Otro consejo se refiere a la cantidad, señalando que debe ser poca ya que pueden oscurecerse: "Se ha de hacer poco de cada uno de estos colores a la vez. [carmin, bermellón y azul de Prusia] singularmente el Carmín porque cada vez se oscurece más, y cuando se acaba de servirse de ellos, cubrirlos muy bien con un papel y meterlos en la caja, porque el aire y el polvo los echa a perder" (Fernández de Olarte 1776).

Buchotte (1743: 9-11) mencionan cómo conseguir ciertos colores a partir de la mezcla de otros: verde (azul y amarillo), anaranjado (rojo y amarillo), gris azulado (negro y azul), morado (azul y rojo). Igualmente Fernández de Olarte (1776) indica lo siguiente: "Azuly Amarillo, hacen verde. Por lo cual la Gomaguta con el Ultramar o el Azul de Prusia hacen un hermosísimo verde. La Gomaguta con el color de Agua bacen también un verdoso. También se hace el de Vejiga echando un poco de color de Agua. Rojo y Amarillo hacen un color madera, de Tierra y de Arena. Poniendo un poco más de uno que de otro; y asi con la Gomaguta y un poco de Carmin se hace un color propio para lavar los fosos secos de las obras; echando un poco menos de Carmin, conviene para la carpintería; echando aun menos conviene para las arenas y poniendo con estos colores muy poca tinta de la China se hace uno que conviene para las Tierras labradas. Negro y Azul hacen un Pardo de Ardoyse', y asi el Azul de Prusia o el Índigo con muy poca tinta de la China, hacen un color muy lindo para lavar todo género de bierro, y echando tinta bien clara conviene perfectamente para el vidrio. El color de Agua, y muy poca tinta de la 
China para lo mismo sirve muy bien, y esto es lo mejor a causa de la dificultad de unirse los otros dos. Azuly Rojo bacen un purpurado muy bello".

\section{Conclusiones}

Los documentos cartográficos de los Ingenieros Militares del s. XVIII son fruto de la combinación de los conocimiento técnicos e intelectuales de la época en la que fueron ejecutados y de las habilidades artísticas de sus autores. Son, por tanto, el resultado de la ciencia y la técnica unidas mediante un proceso artístico.

Constituyen un patrimonio documental que debe ser conservado y que merece ser estudiado puesto que forma parte de la Historia de España en una época en la que la monarquía española tenía posesiones territoriales en distintos continentes.

La información recogida en los textos consultados, tratados de dibujo y lavado de planos y cuadernos de apuntes, demuestran la existencia de una normalización relacionada con la naturaleza de los pigmentos y colorantes utilizados, sus mezclas, los colores que proporcionaban y las áreas representadas en los planos realizados.

El código de color establecido hizo posible que estos documentos cartográficos sirvieran como sistemas de transmisión de información entre los distintos técnicos que participaban en la ejecución y supervisión de un determinado proyecto constructivo.

Los datos aportados en este artículo pueden facilitar la interpretación de los análisis efectuados sobre este tipo de documentos, que tengan por objetivo la caracterización analítica de los pigmentos y colorantes empleados en su ejecución.

\section{Agradecimientos}

Este trabajo forma parte del Proyecto de Investigación I+D HUM2005/04618 financiado por el Ministerio de Educación y Ciencia. Los autores agradecen la colaboración del Archivo Cartográfico y de Estudios Geográficos del Centro Geográfico del Ejército de Tierra (C.E.G.E.T.) (Ministerio de Defensa).

\section{Notas}

[1] Ambas casas reales (Habsburgo y Borbón) eran aspirantes al trono español y esta situación se resolvió con la guerra de Sucesión y el advenimiento definitivo de los Borbones a la monarquía española.

[2] La cola de Flandes se hacía con restos de piel y cartílagos de cabra y cordero.

[3] Según se indica en el texto, los lápices Conté tienen cuatro numeraciones, el $\mathrm{n}^{\circ} 1$ corresponde a los más duros y el no 4 a los más blandos.

[4] Según el Diccionario de Autoridades, el término de cortadillo se refiere a un vaso pequeño para beber, liso y tan ancho de arriba como de abajo, que por lo regular es de vidrio; aunque también se suele hacer de plata. REAL ACADEMIA ESPAÑOLA (RAE): Diccionario de Autoridades, 3 Vols. (1726 1737), Edición facsímil, Ed. Gredos, Madrid, 1990, Vol. 1, p.624

[5] La antigua Siam comprendía la actual Tailandia, además de Camboya, Malasia y Laos. 
[6] Cambaudia es la actual Camboya.

[7] Pardo de Ardoyse: Color gris claro.

\section{Bibliografía}

ANÓNIMO (c. 1770). Architectura Militar i Civil. Texto manuscrito (No inventario 15010) (Fundación Lázaro Galdiano). Madrid.

BÁEZ AGLIO, M. I., SAN ANDRÉS MOYA, M. (1999). "Las lacas rojas de origen natural (I): Naturaleza, Composición y Terminología”, Pátina, 9: 124 -134.

BALLARD CH. (Impresor) (1697). L'Art de Dessiner proprement les Plans, Profils, Elevations Geometrales et Perspectives soit d'Architecture Militaire et Civile avec tous les secrets les plus rares pour faire les couleurs avec lesquelles les Ingenieurs represent les divers materiaux d'une Place. París.

BORDINI, S. (1995). Materia e Imagen. Fuentes sobre las técnicas de la pintura, Barcelona: Ed. del Serbal.

BRUQUETAS, R. (2000). Técnicas y materiales de la pintura española en los siglos de oro, Madrid: Fundación de Apoyo a la Historia del Arte Hispánico.

BUCHOTTE, M. (1743). Les Règles du Dessein et du Lavis puor les plans des ouvrages et des bâtimens, tant de l'Architecture militaire que civile. París : Impreso por A. Jombert.

BURÓN CASTRO, T. (2007). "Papeles especiales: usos, formatos y filigranas", en Actas del VII Congreso Nacional de Historia del Papel. Asociación Hispánica de Historiadores del Papel, El Paular (Rascafría) (23 - 28 de Junio), Madrid, 11-39.

CAPEL, H., SÁNCHEZ, J. E., MONCADA, O (1988). De Palas a Minerva. La formación científica y estructura institucional de los Ingenieros Miltiares en el siglo XVIII. Barcelona: CSIC y Ed. del Serbal.

CARDON, D. (2003). Le monde des teintures naturelles, París: Ed. Belin.

D. J. A. y L. (1833). Método Práctico para el Dibujo Lavado, Pintura de Aguada y de Iluminación. Imprenta de J. Verdaguer. Barcelona: Copia Facsímil de Librerías París-Valencia.

DE LA ROJA, J. M., SAN ANDRÉS, M., SANCHO, N., SANTOS, S. (2007). "Variations in the colorimetric characteristics of verdigris films depending on the process used to produce the pigment and the type of binding agent used in applying it", Color Research and Application, 32: 414-423.

EAStaugH, N., WALSH, V., CHAPlin, T., SIDDALL, R. (2004). Pigment Compendium: A Dictionary of Historical Pigments, Oxford: Elsevier.

FERNÁNDEZ DE MEDRANO, S. (1708). El Architecto Perfecto en el Arte Militar. Tomo V. Impreso en Amberes.

FERNÁNDEZ DE OLARTE, J. (1776). Apuntes sobre dibujo y arquitectura, MSS/13694, Biblioteca Nacional de España.

GAUTIER DE NISMES, H. (1687). L'art de laver ou nouvelle manière de peindre sur le papier, suivant le coloris des desseins qu'on envoye à la Cour. Chez. Thomas Amaulry, Lyon. Facsimil, Portland, Oregon: Ed. Collegium Graphicum, 1972.

GETTENS, R. J., STOUT, G. L. (1966): Paintings Materials. A Short Encyclopedia, New York: Dover Publications.

GIMÉNEZ PRADES, M. (2007). "Documentos Cartográficos del Cuerpo de Ingenieros Militares en el siglo XVIII”, Trabajo de Investigación presentado para la obtención del Diploma de Estudios Avanzados [DEA], 
Dirigido por Margarita San Andrés Moya, Departamento de Pintura (Pintura y Restauración), Facultad de Bellas Artes, Universidad Complutense de Madrid (Octubre 2007).

HARLEY, R. D. (1982). Artists 'Pigments c. 1600 - 1835, London: Butterworths.

HERNÁNDEZ DE GREGORIO, M. (1803). Diccionario elemental de Farmacia, Botánica, y materia médica o aplicaciones de los fundamentos de la Química moderna. Tomo segundo, Madrid: Imprenta Real.

HIDALGO BRINQUIS, M. C. (1980). "Hallazgo de un breve tratado del siglo XIX con recetas para barnizar papel y una descripción detallada de los materiales usados para el diseño y coloración de los planos", en Actas II Congreso de Conservación de Bienes Culturales, Teruel (23 a 25 de junio), 1978: 225-230.

HOFENK DE GRAAFF, J. H. (2004). The Colourful Past. Origins, Chemistry and Identification of Natural Dyestuffs, London: Archetype Publications.

KÜHN, H. (1993). "Verdigris and Copper Resinate", en A. Roy (Ed), Artists' Pigments. A Handbook of their History and Characteristics, Vol. 2, Oxford: Oxford University Press, 131-158.

PORTUGUÉS, J. A. (1803). Colección General de las Ordenanzas Militares, sus innovaciones, y aditamentos, Dispuesta en diez Tomos, con separación de clases. Tomo VI: Real Cuerpo de Artillería e Ingenieros. Madrid: Imprenta de Antonio Marín.

SAN ANDRÉS, M., DE LA ROJA, J. M., SANCHO, N. (2009). "Verdigris, a pigment with different hues. Relation between chemical composition and colour" en Actas $3^{\text {rd }}$ Sysposium Lasmac 2009 \& The Archaeological and Art Issues in Material Science, Cancun (Mexico), 16 $6^{\text {th }}-21^{\text {st }}$ August (2009), (pendiente de publicación).

SANTOS, S., SAN ANDRÉS M., BALDONEDO J. L., RODRÍGUEZ A., DE LA ROJA, J. M., GARCÍABAONZA, V. (2002). "Procesos de obtención del verdigrís. Revisión y reproducción de antiguas recetas. Primeros resultados", en Actas I Congreso del GEIIC. Conservación del Patrimonio, Evolución y nuevas perspectivas, Valencia, 383-388.

SANTOS, S., SAN ANDRÉS, M., BALDONEDO, J. L., RODRÍGUEZ, A. (2003). "Recetas de preparación del verdigrís. Resultados preliminares de la obtención de la variedad conocida como viride salsum". Pátina, 12: 41-52.

SCOTT, D., TANIGUCHI, Y., KOSETO, E. (2001). "The verosimilitude of verdigris: a review of the copper carboxylates", Reviews in Conservation, 2: 75-91.

SCHWEEPPE, H., ROOSEN-RUNGE, H. (1986). "Carmine - Cochineal Carmine and Kermes Carmine", en R.L. Feller (Ed), Artists' Pigments. A Handbook of their History and Characteristics, Vol. 1, Oxford: Oxford University Press, 255-283.

WINTER, J. (1997). "Gamboge", en E. W. Fitzhugh (Ed), Artists'Pigments. A Handbook of Their History and Characteristics, Vol. 3, Oxford: Oxford University Press, 143-155. 


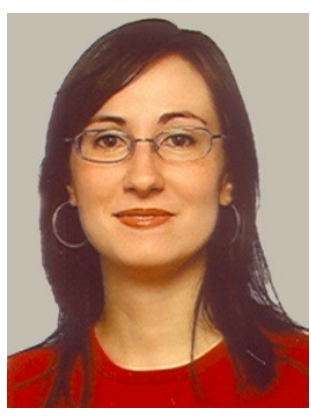

\section{Maria Giménez Prades}

Universidad Complutense de Madrid. Facultad de Bellas Artes.

Departamento de Pintura (Pintura y Restauración).

c/ Greco n 2. (28040). Madrid

Licenciada en Bellas Artes (Especialidad en restauración) por la Universidad Complutense de Madrid. Master en Conservación Preventiva de Obras de Arte y BBCC (Titulo Propio de la UCM)

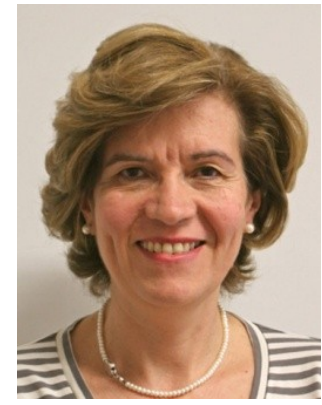

\section{Margarita San Andrés Moya}

Universidad Complutense de Madrid. Facultad de Bellas Artes. Departamento de Pintura (Pintura y Restauración). c/ Greco no 2. (28040). Madrid email: msam@art.ucm.es

Doctora en Ciencias Químicas. Profesora Titular del Departamento de Pintura (Pintura y Restauración) de la Facultad de Bellas Artes (Universidad Complutense de Madrid). Investigadora Principal del Grupo de Investigación 930420 de la UCM (Técnicas de Documentación, Conservación y Restauración de Obras de Arte). Responsable del Laboratorio de Química del Departamento de Pintura de la UCM.

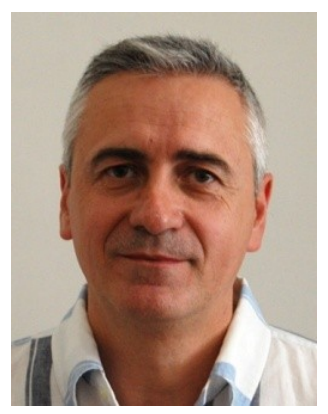

José Manuel de la Roja de la Roja

Doctor en Bellas Artes. Licenciado en Bellas Artes (especialidad Restauración) por la UCM. Colaborador Honorifico del Departamento de Pintura (Pintura y Restauración). Miembro del grupo de investigación 930420 de la UCM. 